Volume: 3

Issue: 1

Page: 9-17

November 2016

\section{How to solve errors-in-variables model for coordinate transformations in a classical adjustment way?}

\author{
Cüneyt Aydın* \\ Yildiz Technical University, Dept. of Geomatics Engineering, Geodesy Division, Esenler-Istanbul, Turkey
}

\begin{abstract}
In a coordinate transformation problem, the coordinates of both systems may have random errors. In such a case, the corresponding problem is considered within the Errors-In-Variables (EIV) model and solved by the method of Weighted Total Least-Squares (WTLS). However there are two main difficulties while applying the WTLS method: (1) A proper cofactor matrix for all elements in the design matrix of the EIV model is also to be formed. This is sometimes confusing work because some elements may be repeated twice or more in the same or different signs and some elements may be error-free coefficients in the design matrix depending on the type of the transformation problem. Hence setting the stochastic part of the model needs a special effort. (2) The derivation of the equations of the WTLS solution is complicated in contrast to the least-squares adjustment. So it may not be easy work to adapt some numerical and statistical methods and ideas to the solution. In order to remove these difficulties this study discusses the solution of the corresponding problem in a classical adjustment way. It is shown mathematically that the adjustment procedure derived for this aim is equivalent to the WTLS solution. Although the procedure is examined here for $2 D$ Affine transformation, it may be easily adapted to other coordinate transformation problems.
\end{abstract}

Keywords

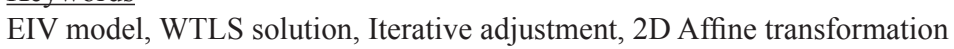

\section{Özet}

\section{Koordinat dönüşümünde EIV model klasik dengeleme yoluyla nasıl çözülür?}

Cilt: 3

Sayı: 1

Sayfa: 9-17

Kasım 2016
Bir koordinat dönüşümü probleminde yalnız bir sistemin değil, her iki sistemin koordinatları rasgele hatalı olabilir. Böylesi bir durumda ilgili problem, EIV model çerçevesinde ele alınır ve WTLS yöntemiyle çözülür. WTLS yönteminin uygulanmasında iki temel zorlukla karşılaşılır: (1) Çözüm için, EIV modelin katsayılar matrisinde geçen tüm elemanlara ilişkin de uygun bir kofaktör matris düşünülmelidir. Dönüşüm probleminin türüne bağlı olarak, katsayılar matrisindeki bazı elemanlar, iki ya da daha fazla kez aynı ya da farklı işaretli olarak geçtiği ve bazı elemanlar da hatasız olabildiği için, bu, her zaman kolay bir işlem değildir. Bu nedenle, modelin stokastik kısmını oluşturmak özel bir çabayı gerektirir. (2) WTLS çözümüne ilişkin eşitliklerin elde edilmesi, bilinen en küçük kareler dengelemesine göre oldukça karmaşıtıtır. Bu da, bazı nümerik ve istatistiki yöntem ve fikirlerin çözüme uyarlanmasını zorlaştırır. Söz konusu zorlukları ortadan kaldırmaya yönelik olarak, bu çalışmada, ilgili problemin çözümünün alışılageldik dengeleme yoluyla nasıl yapılacağı irdelenmektedir. Bu amaçla oluşturulan bir dengeleme işleminin WTLS çözümüne denk olduğu, matematiksel olarak gösterilmektedir. Söz konusu dengeleme işleminin çıkarımı, burada 2B Afin dönüşümü için çalışılmıştır, ancak, herhangi bir koordinat dönüşümüne kolayca uyarlanabilecek biçimde anlatılmıştır.

Anahtar Sözcükler

EIV model, WTLS çözümü, İteratif dengeleme, 2B Afin dönüşümü

\footnotetext{
* Corresponding Author:

E-mail: caydin@yildiz.edu.tr, caydin78@gmail.com
} 


\section{Introduction}

In adjustment problems, the design matrix of the adjustment model constitutes error-free elements. However in some situations like line or plane fitting and coordinate transformations, some elements in the design matrix may be contaminated with random errors. In such a case, the estimation model is established as the Errors-In-Variables (EIV) model (Golub and Van Loan 1980; Carroll and Ruppert 1996; van Huffel 2004). The EIV model with full cofactor matrix of observables is solved by the method of Weighted Total Least-Squares (WTLS) (Schaffrin and Wieser 2008). In geodesy this method is generally applied to planar coordinate transformation problems in which both system coordinates are burdened with random errors.

The WTLS method is based on a Lagrangian function to obtain the minimum of the weighted sum of the squared all errors under a condition equation system. Different ways followed while solving the function lead to different iterative algorithms. Fang $(2011 ; 2013)$ and Snow (2012) give remarkable details about them. According to Aydin et al. (2014) the iterative algorithms may be classified into three groups; (1) generalized normal equation based-WTLS algorithm (Snow 2012), (2) least-squares based-WTLS algorithm (Snow 2012; Amiri-Simkooei and Jazaeri 2012) and (3) improved WTLS algorithm (Tong et al. 2011). There are also other solution ways. But they also lead to similar algorithms. For instance, the EIV model may be transformed to a nonlinear Gauss-Helmert model using some matrix identities (Schaffrin and Snow 2010; Snow 2012). Its proper least-squares solution yields the same iterative equations with the second algorithm (see Section 3).

The algorithms give the same numerical results. However there are two common difficulties in their application: (1) They need a special cofactor matrix, which is obtained from the cofactor matrix of the observables (coordinates) by a proper modification (see Section 2). To get this cofactor matrix, a special effort should be consumed especially for the correlated observables; (2) The equations of the WTLS algorithms are complicated in constrast to the well-known least-squares adjustment equalities. Therefore it may not be easy to adapt some numerical and statistical methods to them. To remove these difficulties this study discusses the solution of the corresponding EIV problem in a classical adjustment way using the ideas of "generalization of TLS" and " general least-squares method" given by Neitzel (2010) and Ghilani and Wolf (2006), respectively. Neitzel (2010) shows how to solve explicitly the EIV problem in 2D similarity transformation example by adapting a usual (Gauss-Helmert type) iterative least-squares adjustment based on the warning of Pope (1972). This kind of adjustment uses the cofactor matrix of the (uncorrelated) coordinates without any modification and more explicit than WTLS algorithms. Neitzel (2010) numerically proves that this iterative adjustment procedure gives the same results with the WTLS solution. On the other hand, "general leastsquares method" mentioned by Ghilani and Wolf(2006) tries to solve the EIV problem using the same iterative adjustment idea of Neitzel (2010) but in a wrong way. In that method, the linearization in the functional part of the transformation problem is realized for "the system coordinates and unknown parameters". To obtain the same results with the WTLS solution, the linearization should be realized for "the errors of the coordinates and unknown parameters". Combining these two studies, we give the iterative adjustment procedure for solving the coordinate transformation problem within the EIV model for correlated observables. For this we organize our study as follows: Section 2 shortly expresses the EIV model and its WTLS solution with the leastsquares based-algorithm. The alternative derivation of this WTLS algorithm by solving the nonlinear Gauss-Helmert model is given in Section 3 as a general review although 2D Affine transformation example is used herein. The iterative adjustment procedure for solving the corresponding problem is presented in Section 4. In that section it is proved mathematically that this kind of adjustment is equivalent to the WTLS solution. Moreover it is shown how to work with the shifted coordinates instead of large coordinates causing some numerical errors during iterative estimation process. A numerical example is given in Section 5. Last section concludes the study.

\section{WTLS Solution}

\section{EIV Model for 2D Affine Transformation}

The standard 2D Affine transformation between $x y$ (target) and $u v$ (start) Cartesian coordinate systems is defined as follows;

$x=t_{1}+u k_{1}-v k_{2} ; y=t_{2}+u k_{3}+v k_{4}$

where $t$ and $k$ denote the (unknown) translation parameter and transformation parameter, respectively. Now suppose that we have $p>3$ identical points whose coordinates, which are collected in $2 p(=n) \times 1$ vectors $\boldsymbol{y}=\left[\ldots x_{i} y_{i} \ldots\right]^{T}$ and $\boldsymbol{s}=\left[\ldots u_{i} v_{i} \ldots\right]^{T}$ in the target and start systems, respectively, are burdened with normally distributed random errors denoted as

$$
\begin{aligned}
\boldsymbol{e} & =\left[\begin{array}{l}
\boldsymbol{e}_{y} \\
\boldsymbol{e}_{s}
\end{array}\right] \\
& =\left[\ldots e_{x i} e_{y i} \ldots e_{u i} e_{v i} \ldots\right]^{T} \sim N\left(\left[\begin{array}{l}
\mathbf{0} \\
\mathbf{0}
\end{array}\right], \sigma^{2}\left[\begin{array}{cc}
\boldsymbol{Q}_{y} & \boldsymbol{Q}_{y s} \\
\boldsymbol{Q}_{s y} & \boldsymbol{Q}_{s}
\end{array}\right]=\sigma^{2} \boldsymbol{Q}_{\mathbf{e}}\right)
\end{aligned}
$$

where $e$ shows the random error; $\boldsymbol{e}_{y}$ and $\boldsymbol{e}_{s}$ are the $n \times 1$ random error vectors of the target and the start system coordinates; $\sigma^{2}$ is the (unknown) variance component and $\boldsymbol{Q}_{j}(j=y, s$ and $y s)$ represents the corresponding coordinate cofactor matrix with $\operatorname{rank} \boldsymbol{Q}_{j}=n$ for $j=y, s$. For these erroneous coordinates of $p$ identical points, from model (1) we get

$$
\begin{aligned}
& x_{i}-e_{x i}=t_{1}+\left(u_{i}-e_{u i}\right) k_{1}-\left(v_{i}-e_{v i}\right) k_{2} \\
& y_{i}-e_{y i}=t_{2}+\left(u_{i}-e_{u i}\right) k_{3}+\left(v_{i}-e_{v i}\right) k_{4} \quad(i=1, \ldots, p)
\end{aligned}
$$

which denotes the functional part of the Errors-in-Variables (EIV) model for the corresponding transformation problem. The common form of the EIV model's functional part is derived by rearranging Eq. (3) as follows; 


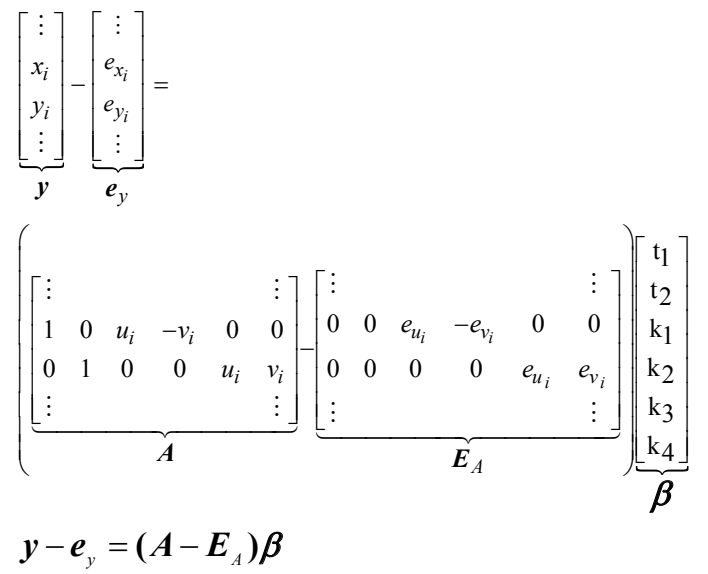

where $\boldsymbol{A}$ is the $n \times 6$ coefficient matrix, the so-called data matrix (see e.g., Snow 2012); $\boldsymbol{\beta}$ is the $6 \times 1$ vector of the unknown parameters and $\boldsymbol{E}_{A}$ is the $n \times 6$ error matrix. For the stochastic part of the EIV model, the covariance matrix $(\boldsymbol{C})$ is established for the error terms of Eq. (4), i.e. for the error vector $\boldsymbol{e}_{y}$ and the error matrix $\boldsymbol{E}_{A}$. As seen from Eq. (4), the error matrix $\boldsymbol{E}_{A}$ consists of the errors of the start system coordinates. In other words, it is the matrix being the function of the error vector $\boldsymbol{e}_{s}$ of the start system. This relationship may be shown as follows;

$\boldsymbol{E}_{A}=\operatorname{vec}^{-1}\left(\boldsymbol{J} \boldsymbol{e}_{s}\right)$ or $\operatorname{vec} \boldsymbol{E}_{A}=\boldsymbol{e}_{A}=\boldsymbol{J} \boldsymbol{e}_{s}$

where vec is the operator stacking one column of a matrix under the other, from left to right; $\mathrm{vec}^{-1}$ is the inverse vec operator reshaping a vector to get a suitable matrix; $\boldsymbol{e}_{A}$ is the $6 n \times 1$ error vector associated with $\boldsymbol{A}\left(\boldsymbol{e}_{A}=\mathrm{vec} \boldsymbol{E}_{A}\right)$ and $\boldsymbol{J}$ is the $6 n \times n$ Jacobian matrix transforming $\boldsymbol{e}_{s}$ to $\boldsymbol{e}_{A}$ (see Appendix A). Then with Eq. (2) and the law of cofactor propagation the distribution of the error vector $\boldsymbol{\gamma}=\left[\boldsymbol{e}_{y} \boldsymbol{e}_{A}\right]^{T}$ is derived as

$\boldsymbol{\gamma}=\left[\begin{array}{c}\boldsymbol{e}_{y} \\ \boldsymbol{e}_{A}\end{array}\right] \sim N\left(\left[\begin{array}{l}\mathbf{0} \\ \mathbf{0}\end{array}\right], \sigma^{2}\left[\begin{array}{cc}\boldsymbol{Q}_{y} & \boldsymbol{Q}_{y s} \boldsymbol{J}^{T} \\ \boldsymbol{J} \boldsymbol{Q}_{s y} & \boldsymbol{J} \boldsymbol{Q}_{s} \boldsymbol{J}^{T}\end{array}\right]=\sigma^{2}\left[\begin{array}{cc}\boldsymbol{Q}_{y} & \boldsymbol{Q}_{y A} \\ \boldsymbol{Q}_{A y} & \boldsymbol{Q}_{A}\end{array}\right]\right)(6)$

Accordingly, models (4) and (6) constitute the EIV model

$\boldsymbol{y}-\boldsymbol{e}_{y}=\left(\boldsymbol{A}-\boldsymbol{E}_{A}\right) \boldsymbol{\beta}, \boldsymbol{C}_{\gamma}=\sigma^{2}\left[\begin{array}{cc}\boldsymbol{Q}_{y} & \boldsymbol{Q}_{y A} \\ \boldsymbol{Q}_{A y} & \boldsymbol{Q}_{A}\end{array}\right]=\sigma^{2} \boldsymbol{Q}_{\gamma}$

\section{WTLS Solution}

Estimating unknown parameters in model (7) is realized by the method of WTLS (Schaffrin and Wieser, 2008). It depends on minimizing the quadratic form (see e.g., Fang 2011; Snow 2012)

$\Omega=\left[\boldsymbol{e}_{y}^{T} \boldsymbol{e}_{A}^{T}\right]\left(\left[\begin{array}{cc}\boldsymbol{Q}_{y} & \boldsymbol{Q}_{y A} \\ \boldsymbol{Q}_{A y} & \boldsymbol{Q}_{A}\end{array}\right]\right)^{-1}\left[\begin{array}{l}\boldsymbol{e}_{y} \\ \boldsymbol{e}_{A}\end{array}\right]$

subject to the constraints " $\boldsymbol{y}-\boldsymbol{e}_{y}=\left(\boldsymbol{A}-\boldsymbol{E}_{A}\right) \boldsymbol{\beta}$ ". For this, considering the vector equality " $\boldsymbol{E}_{A} \boldsymbol{\beta}=\left(\boldsymbol{\beta}^{T} \otimes \boldsymbol{I}_{n}\right) \mathbf{e}_{A}$ " (Koch 1999), the following target (Lagrangian) function is used;

$$
\begin{aligned}
\phi & =\Omega+2 \lambda^{T}\left(\boldsymbol{y}-\boldsymbol{e}_{y}-\boldsymbol{A} \boldsymbol{\beta}+\boldsymbol{E}_{A} \boldsymbol{\beta}\right) \\
& =\Omega+2 \boldsymbol{\lambda}^{T}\left(\boldsymbol{y}-\boldsymbol{e}_{y}-\boldsymbol{A} \boldsymbol{\beta}+\left(\boldsymbol{\beta}^{T} \otimes \boldsymbol{I}_{n}\right) \boldsymbol{e}_{A}\right)
\end{aligned}
$$

where $\lambda$ is the $n \times 1$ vector of Lagrange multiplers; $\otimes$ is the Kronecker product and $\boldsymbol{I}_{n}$ is the $n \times n$ identity matrix. By the Euler condition equations obtained from the partial derivatives of Eq. (9) according to $\boldsymbol{e}_{y}, \boldsymbol{e}_{A}, \boldsymbol{\beta}$ and $\boldsymbol{\lambda}$ (see, e.g., Snow 2012) the following equations are obtained;

$\tilde{\boldsymbol{e}}_{A}=\left(\boldsymbol{Q}_{A y}-\boldsymbol{Q}_{A}\left(\hat{\boldsymbol{\beta}} \otimes \boldsymbol{I}_{n}\right)\right) \hat{\boldsymbol{\lambda}}, \tilde{\boldsymbol{E}}_{A}=\operatorname{vec}^{-1}\left(\tilde{\boldsymbol{e}}_{A}\right)$

$\tilde{\boldsymbol{e}}_{y}=\left(-\boldsymbol{Q}_{y A}\left(\hat{\boldsymbol{\beta}} \otimes \boldsymbol{I}_{n}\right)+\boldsymbol{Q}_{y}\right) \hat{\boldsymbol{\lambda}}$

$\boldsymbol{Q}_{1} \hat{\boldsymbol{\lambda}}=\boldsymbol{y}-\boldsymbol{A} \hat{\boldsymbol{\beta}}$ with

$$
\begin{aligned}
& \boldsymbol{Q}_{1}=\boldsymbol{Q}_{y}-\boldsymbol{Q}_{y A}\left(\hat{\boldsymbol{\beta}} \otimes \boldsymbol{I}_{n}\right)-\left(\hat{\boldsymbol{\beta}} \otimes \boldsymbol{I}_{n}\right)^{T} \boldsymbol{Q}_{A y} \\
& \quad+\left(\hat{\boldsymbol{\beta}} \otimes \boldsymbol{I}_{n}\right)^{T} \boldsymbol{Q}_{A}\left(\hat{\boldsymbol{\beta}} \otimes \boldsymbol{I}_{n}\right) \\
& \left(\boldsymbol{A}-\tilde{\boldsymbol{E}}_{\mathrm{A}}\right)^{T} \hat{\boldsymbol{\lambda}}=\mathbf{0}
\end{aligned}
$$

where " $\sim$ " and "^" show the predicted and estimated values, respectively. Using Eqs.(10c-d), the following normal equations are written;

$$
\left[\begin{array}{cc}
\boldsymbol{Q}_{1} & \boldsymbol{A}-\tilde{\boldsymbol{E}}_{A} \\
\left(\boldsymbol{A}-\tilde{\boldsymbol{E}}_{\mathrm{A}}\right)^{T} & \boldsymbol{0}
\end{array}\right]\left[\begin{array}{l}
\hat{\boldsymbol{\lambda}} \\
\hat{\boldsymbol{\beta}}
\end{array}\right]=\left[\begin{array}{c}
\boldsymbol{y}-\tilde{\boldsymbol{E}}_{A} \hat{\boldsymbol{\beta}} \\
\mathbf{0}
\end{array}\right]
$$

Eliminating the multiplier vector $\hat{\lambda}$ from Eq. (11) yields

$$
\left(\boldsymbol{A}-\tilde{\boldsymbol{E}}_{A}\right)^{T} \boldsymbol{Q}_{1}^{-1}\left(\boldsymbol{A}-\tilde{\boldsymbol{E}}_{A}\right) \hat{\boldsymbol{\beta}}=\left(\boldsymbol{A}-\tilde{\boldsymbol{E}}_{A}\right)^{T} \boldsymbol{Q}_{1}^{-1}\left(\boldsymbol{y}-\tilde{\boldsymbol{E}}_{A} \hat{\boldsymbol{\beta}}\right)
$$

Both sides of Eq. (12) include the parameter vector $\hat{\boldsymbol{\beta}}$, therefore there is no a direct solution. It may only be solved iteratively. For the iterative solution, initial values for $\boldsymbol{\beta}$ and $\boldsymbol{E}_{A}$ are needed. Having assumed that only the target system coordinates are burdened with random errors, these initial values are obtained by

$\hat{\boldsymbol{\beta}}_{0}=\left(\boldsymbol{A}^{T} \boldsymbol{Q}_{y}^{-1} \boldsymbol{A}\right)^{-1} \boldsymbol{A}^{T} \boldsymbol{Q}_{y}^{-1} \boldsymbol{y}, \tilde{\boldsymbol{E}}_{A, 0}=\mathbf{0}$

Taking Eqs. (10) to (13) into consideration, the iterative solution algorithm (least-squares based-algorithm) may be designed as given in Appendix B (Snow 2012). The parameter vector $\hat{\boldsymbol{\beta}}$ and the error vector $\tilde{\boldsymbol{e}}_{A}$ are obtained as soon as the algorithm converges to the solution. The error vector $\tilde{\boldsymbol{e}}_{y}$ is, on the other hand, computed from Eq. (10b) using the estimated parameter vector $\hat{\boldsymbol{\beta}}$ at the last iteration. Accordingly the covariance matrix of the estimated parameters is obtained as follows (Amiri-Simkooei and Jazaeri 2012);

$\boldsymbol{C}_{\hat{\beta}}=\hat{\sigma}^{2}\left[\left(\boldsymbol{A}-\tilde{\boldsymbol{E}}_{A}\right)^{T} \boldsymbol{Q}_{1}^{-1}\left(\boldsymbol{A}-\tilde{\boldsymbol{E}}_{A}\right)\right]^{-1}$ with

$\hat{\sigma}^{2}=\tilde{\Omega} /(n-6)$

where $\widetilde{\Omega}$ is the quadratic form computed from Eq. (8) by the error vectors $\tilde{\boldsymbol{e}}_{y}$ and $\tilde{\boldsymbol{e}}_{A}$. 


\section{Alternative Derivation of WTLS Solution}

The EIV model (7) may be written as follows;

$$
\begin{aligned}
\left(\boldsymbol{A}-\boldsymbol{E}_{A}\right) \boldsymbol{\beta}-\left(\boldsymbol{y}-\boldsymbol{e}_{y}\right) & =\boldsymbol{A} \boldsymbol{\beta}+\underbrace{\left[\boldsymbol{I}_{n}-\left(\boldsymbol{\beta}^{T} \otimes \boldsymbol{I}_{n}\right)\right.}_{B}] \\
& \underbrace{\left[\begin{array}{l}
\boldsymbol{e}_{y} \\
\boldsymbol{e}_{A}
\end{array}\right]}_{\gamma}-\boldsymbol{y} \\
& =\Psi(\boldsymbol{\beta}, \boldsymbol{\gamma})=\boldsymbol{A} \boldsymbol{\beta}+\boldsymbol{B} \gamma-\boldsymbol{y}=\mathbf{0}
\end{aligned}
$$

with $\boldsymbol{C}_{\gamma}=\sigma_{0}^{2} \boldsymbol{Q}_{\gamma}$

Model (15) defines the nonlinear Gauss-Helmert model. It may be solved adapting an iterative linearization scheme. First we need to assign approximate values for $\boldsymbol{\beta}$ and $\boldsymbol{\gamma}$, say $\boldsymbol{\beta}_{0}$ and $\boldsymbol{\gamma}_{0}$ (see Eq.(24)). Then model (15) may be linearized initially using Taylor series expansion as

$$
\psi(\boldsymbol{\beta}, \boldsymbol{\gamma})=\psi\left(\boldsymbol{\beta}_{0}, \boldsymbol{\gamma}_{0}\right)+\left.\frac{\partial \psi}{\partial \boldsymbol{\beta}^{T}}\right|_{0}\left(\boldsymbol{\beta}-\boldsymbol{\beta}_{0}\right)+\left.\frac{\partial \psi}{\partial \boldsymbol{\gamma}^{T}}\right|_{0}\left(\boldsymbol{\gamma}-\boldsymbol{\gamma}_{0}\right) \doteq \mathbf{0}
$$

The partial derivatives and the approximate function value $\psi\left(\boldsymbol{\beta}_{0}, \boldsymbol{\gamma}_{0}\right)$ are obtained from Eq. (15) as follows;

$$
\left.\frac{\partial \psi}{\partial \boldsymbol{\beta}^{T}}\right|_{0}=\left(\boldsymbol{A}-\boldsymbol{E}_{A, 0}\right),\left.\frac{\partial \psi}{\partial \boldsymbol{\gamma}^{T}}\right|_{0}=\boldsymbol{B}_{0}=\left[\begin{array}{ll}
\boldsymbol{I}_{n} & -\left(\boldsymbol{\beta}^{T} \otimes \boldsymbol{I}_{n}\right)
\end{array}\right]
$$

and $\psi\left(\boldsymbol{\beta}_{0}, \boldsymbol{\gamma}_{0}\right)=\left(\boldsymbol{A}-\boldsymbol{E}_{A, 0}\right) \boldsymbol{\beta}_{0}-\left(\boldsymbol{y}-\boldsymbol{e}_{y, 0}\right)$

Substituting Eq. (17) into Eq. (16) results in $\left(\boldsymbol{A}-\boldsymbol{E}_{A, 0}\right) \boldsymbol{\beta}_{0}-\left(\boldsymbol{y}-\boldsymbol{e}_{y, 0}\right)+\left(\boldsymbol{A}-\boldsymbol{E}_{A, 0}\right)\left(\boldsymbol{\beta}-\boldsymbol{\beta}_{0}\right)+\boldsymbol{B}_{0}\left(\boldsymbol{\gamma}-\boldsymbol{\gamma}_{0}\right) \doteq \mathbf{0}(18 \mathrm{a})$ or

$$
\left(\boldsymbol{A}-\boldsymbol{E}_{A, 0}\right) \boldsymbol{\beta}+\boldsymbol{B}_{0} \gamma=\left(\boldsymbol{y}-\boldsymbol{e}_{y, 0}\right)+\boldsymbol{B}_{0} \gamma_{0}
$$

The right hand side of Eq. (18b) shows the misclosure vector. Using $\boldsymbol{B}_{0}$ in Eq. (17) it becomes

$$
\begin{aligned}
\left(\boldsymbol{y}-\boldsymbol{e}_{y, 0}\right)+\boldsymbol{B}_{0} \gamma_{0} & =\boldsymbol{y}-\boldsymbol{e}_{y, 0}+\boldsymbol{e}_{y, 0}-\left(\boldsymbol{\beta}_{0}{ }^{T} \otimes \boldsymbol{I}_{n}\right) \boldsymbol{e}_{A, 0} \\
& =\boldsymbol{y}-\boldsymbol{E}_{A, 0} \boldsymbol{\beta}_{0}
\end{aligned}
$$

With Eqs. (18b) and (19), finally the following (linear) Gauss-Helmert model is obtained;

$$
\left(\boldsymbol{A}-\boldsymbol{E}_{A, 0}\right) \boldsymbol{\beta}+\boldsymbol{B}_{0} \boldsymbol{\gamma}=\boldsymbol{y}-\boldsymbol{E}_{A, 0} \boldsymbol{\beta}_{0} \text { with } \boldsymbol{C}_{\gamma}=\sigma_{0}^{2} \boldsymbol{Q}_{\gamma}
$$

which denotes the initial linear form of model (15). It is now solvable by the method of least-squares. Applying the solution methodology given in Koch (1999) first estimate for $\boldsymbol{\beta}$ and prediction for $\boldsymbol{\gamma}$ are obtained as follows;

$$
\begin{aligned}
\hat{\boldsymbol{\beta}}_{1} & =\left[\left(\boldsymbol{A}-\boldsymbol{E}_{A, 0}\right)^{T} \boldsymbol{Q}_{1,1}^{-1}\left(\boldsymbol{A}-\boldsymbol{E}_{A, 0}\right)\right]^{-1}\left(\boldsymbol{A}-\boldsymbol{E}_{A, 0}\right)^{T} \boldsymbol{Q}_{1,1}^{-1}\left(\boldsymbol{y}-\boldsymbol{E}_{A, 0} \boldsymbol{\beta}_{0}\right) \\
\tilde{\gamma}_{1} & =\left[\begin{array}{l}
\tilde{\boldsymbol{e}}_{y, 1} \\
\tilde{\boldsymbol{e}}_{A, 1}
\end{array}\right] \\
& =\underbrace{\left(\left[\begin{array}{l}
\boldsymbol{Q}_{y}-\boldsymbol{Q}_{y A}\left(\boldsymbol{\beta}_{0} \otimes \boldsymbol{I}_{n}\right) \\
\boldsymbol{Q}_{A y}-\boldsymbol{Q}_{A}\left(\boldsymbol{\beta}_{0} \otimes \boldsymbol{I}_{n}\right)
\end{array}\right]\right)}_{\boldsymbol{Q}_{\gamma} \boldsymbol{B}_{0}^{T}} \boldsymbol{Q}_{1,1}^{-1}\left(\boldsymbol{y}-\boldsymbol{E}_{A, 0} \boldsymbol{\beta}_{0}-\left(\boldsymbol{A}-\boldsymbol{E}_{A, 0}\right) \hat{\boldsymbol{\beta}}_{1}\right)
\end{aligned}
$$

where $\boldsymbol{Q}_{1,1}$ is the cofactor matrix of the error term $\boldsymbol{B}_{0} \boldsymbol{\gamma}$, which is obtained by

$$
\begin{aligned}
\boldsymbol{Q}_{1,1} & =\boldsymbol{B}_{0} \boldsymbol{Q}_{\gamma} \boldsymbol{B}_{0}^{T} \\
& =\boldsymbol{Q}_{y}-\boldsymbol{Q}_{y A}\left(\boldsymbol{\beta}_{0} \otimes \boldsymbol{I}_{n}\right)-\left(\boldsymbol{\beta}_{0} \otimes \boldsymbol{I}_{n}\right)^{T} \boldsymbol{Q}_{A y} \\
& +\left(\boldsymbol{\beta}_{0} \otimes \boldsymbol{I}_{n}\right)^{T} \boldsymbol{Q}_{A}\left(\boldsymbol{\beta}_{0} \otimes \boldsymbol{I}_{n}\right)
\end{aligned}
$$

Similar to Eq. (13), the (initial) approximate values for $\boldsymbol{\beta}$ and $\gamma$ are assumed as

$$
\begin{aligned}
& \boldsymbol{\beta}_{0}=\hat{\boldsymbol{\beta}}_{0}=\left(\boldsymbol{A}^{T} \boldsymbol{Q}_{y}^{-1} \boldsymbol{A}\right)^{-1} \boldsymbol{A}^{T} \boldsymbol{Q}_{y}^{-1} \boldsymbol{y} \\
& \boldsymbol{\gamma}_{0}=\hat{\boldsymbol{\gamma}}_{0}=\left[\tilde{\boldsymbol{e}}_{y, 0} \tilde{\boldsymbol{e}}_{A, 0}\right]^{T}=\left[\begin{array}{ll}
\boldsymbol{0} & \boldsymbol{0}
\end{array}\right]^{T} \text { and } \boldsymbol{E}_{A, 0}=\tilde{\boldsymbol{E}}_{A, 0}=\mathbf{0}
\end{aligned}
$$

Then it is seen that the solutions between Eq. (21) and Eq. (23) are identical with the first iteration equations of the least-squares-based WTLS algorithm. The linearization/ solution of the nonlinear Gauss-Helmert model (15) is maintained iteratively using the same iterative formulae. Hence it is proved that this kind of solution is equivalent to the WTLS solution.

\section{Iterative Adjustment Procedure for EIV Model}

For 2D Affine transformation example, "general least-squares method" in Ghilani and Wolf (2006) depends on linearizing the functional relationship in Eq. (3) according to the random variables " $x y$ and $u v$ coordinates and unknown parameters" and solving the resulting Gauss-Helmert model. However the linearization should be realized for "the random errors of the system coordinates and unknown parameters", as shown in Neitzel (2010). Considering these two studies, the iterative adjustment procedure for solving the corresponding transformation problem within the EIV model for correlated coordinates is explicitly derived here in. It is also proved that this kind of adjustment procedure is equivalent to the leastsquares based-WTLS algorithm.

Let us subtract the (unknown) translation parameters $\left(t_{1}\right.$ and $\left.t_{2}\right)$ from Eq. (3)

$$
\begin{aligned}
& F_{i}=x_{i}-e_{x i}-t_{1}=\left(u_{i}-e_{u i}\right) k_{1}-\left(v_{i}-e_{v i}\right) k_{2} \\
& G_{i}=y_{i}-e_{y i}-t_{2}=\left(u_{i}-e_{u i}\right) k_{3}+\left(v_{i}-e_{v i}\right) k_{4}(i=1, \ldots, p)
\end{aligned}
$$

The above functions $\boldsymbol{F}_{i}$ and $\boldsymbol{G}_{i}$ are nonlinear functions of the errors $e_{u}$ and $e_{v}$ in the start system coordinates and the unknown transformation parameters $k_{j}(j=1, \ldots, 4)$. They may be linearized by Taylor series expansion. For this, the corresponding errors and parameters are partitioned into two parts

$e_{u i}=e_{u i, 0}+\delta e_{u i}, e_{v i}=e_{v i, 0}+\delta e_{v i}, k_{j}=k_{j, 0}+\delta k_{j}$

$(j=1, \ldots, 4)$

where " $\delta$ " shows the small deviation from the approximate value $(\ldots)_{0}$. The function $F_{i}$ then may be written as 


$$
\begin{aligned}
F_{i} & =F_{i, 0}+\left.\frac{\partial F_{i}}{\partial e_{u i}}\right|_{0} \delta e_{u i}+\left.\frac{\partial F_{i}}{\partial e_{v i}}\right|_{0} \delta e_{v i}+\left.\frac{\partial F_{i}}{\partial k_{1}}\right|_{0} \delta k_{1}+\left.\frac{\partial F_{i}}{\partial k_{2}}\right|_{0} \delta k_{2} \\
& =\left(u_{i}-e_{u i, 0}\right) k_{1,0}-\left(v_{i}-e_{v i, 0}\right) k_{2,0}-k_{1,0} \delta e_{u i}+k_{2,0} \delta e_{v i} \\
& +\left(u_{i}-e_{u i, 0}\right) \delta k_{1}-\left(v_{i}-e_{v i, 0}\right) \delta k_{2}
\end{aligned}
$$

With Eq. (26), Eq. (27a) may be rearranged as

$$
\begin{aligned}
F_{i} & =\left(u_{i}-e_{u i, 0}\right) k_{1}-\left(v_{i}-e_{v i, 0}\right) k_{2}-k_{1,0} \delta e_{u i}+k_{2,0} \delta e_{v i} \\
& =\left(u_{i}-e_{u i, 0}\right) k_{1}-\left(v_{i}-e_{v i, 0}\right) k_{2}-k_{1,0}\left(e_{u i}-e_{u i, 0}\right) \\
& +k_{2,0}\left(e_{v i}-e_{v i, 0}\right)
\end{aligned}
$$

Substituting Eq. (27b) into Eq. (25) results in

$$
\begin{aligned}
x_{i}-\left(e_{u i, 0} k_{1,0}-e_{v i, 0} k_{2,0}\right) & =t_{1}+\left(u_{i}-e_{u i, 0}\right) k_{1}-\left(v_{i}-e_{v i, 0}\right) k_{2} \\
& +\left(e_{x i}-k_{1,0} e_{u i}+k_{2,0} e_{v i}\right)
\end{aligned}
$$

$(i=1, \ldots, p)$

From the function $G_{i}$ in Eq. (25), similarly the following equations are obtained;

$$
\begin{aligned}
y_{i}-\left(e_{u i, 0} k_{3,0}+e_{v i, 0} k_{4,0}\right)= & t_{2}+\left(u_{i}-e_{u i, 0}\right) k_{3}+\left(v_{i}-e_{v i, 0}\right) k_{4} \\
& +\left(e_{y i}-k_{3,0} e_{u i}-k_{4,0} e_{v i}\right)
\end{aligned}
$$

$(i=1, \ldots, p)$

Eq. (28) represents the observation equations which may be written in matrix form as follows;

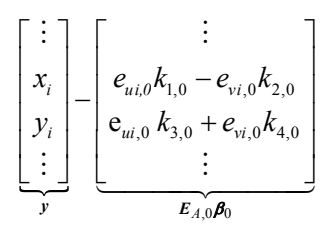

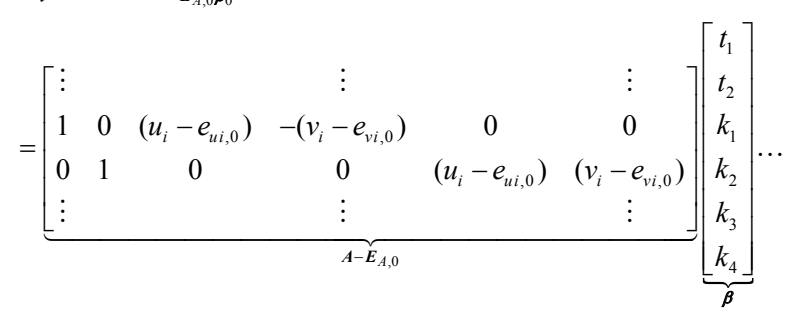$$
+\underbrace{\left[\begin{array}{c}
\vdots \\
e_{x i}-k_{1,0} e_{u i}+k_{2,0} e_{v i} \\
e_{y i}-k_{3,0} e_{u i}-k_{4,0} e_{v i} \\
\vdots
\end{array}\right]}_{\boldsymbol{\varepsilon}_{0}} \rightarrow \boldsymbol{y}-\boldsymbol{E}_{A, 0} \boldsymbol{\beta}_{0}=\left(\boldsymbol{A}-\boldsymbol{E}_{A, 0}\right) \boldsymbol{\beta}+\boldsymbol{\varepsilon}_{0}
$$

where $\boldsymbol{\beta}_{0}$ and $\boldsymbol{E}_{A, 0}$ denote the approximate parameter vector and error matrix, respectively, as in Eq. (17) and $\boldsymbol{\varepsilon}_{0}$ is the error term formed by

$$
\boldsymbol{\varepsilon}_{0}=\boldsymbol{D}_{0} \boldsymbol{e}=\left[\begin{array}{ll}
\boldsymbol{I}_{n} & \boldsymbol{F}_{0}
\end{array}\right]\left[\begin{array}{l}
\boldsymbol{e}_{y} \\
\boldsymbol{e}_{s}
\end{array}\right]=\left[\begin{array}{ll}
\boldsymbol{I}_{n} & \left(\boldsymbol{I}_{n} \otimes \boldsymbol{K}_{0}\right)
\end{array}\right]\left[\begin{array}{l}
\boldsymbol{e}_{y} \\
\boldsymbol{e}_{s}
\end{array}\right]
$$

with $\boldsymbol{K}_{0}=\left[\begin{array}{cc}-k_{1,0} & k_{2,0} \\ -k_{3,0} & -k_{4,0}\end{array}\right]$
Since the error term $\boldsymbol{\varepsilon}_{0}$ depends on the original total error vector e, with Eqs. (2), (29) and (30) the following (linear) Gauss-Helmert model is written;

$$
\left(\boldsymbol{A}-\boldsymbol{E}_{A, 0}\right) \boldsymbol{\beta}+\boldsymbol{D}_{0} \boldsymbol{e}=\boldsymbol{y}-\boldsymbol{E}_{A, 0} \boldsymbol{\beta}_{0}, \boldsymbol{C}_{e}=\sigma_{0}^{2} \boldsymbol{Q}_{e}
$$

Model (31) is equivalent to model (20) because the error term $\boldsymbol{B} \boldsymbol{\gamma}$ of model (15) holds

$$
\begin{aligned}
\boldsymbol{B} \boldsymbol{\gamma} & =\left[\begin{array}{ll}
\boldsymbol{I}_{\mathrm{n}} & -\left(\boldsymbol{\beta}^{T} \otimes \boldsymbol{I}_{n}\right)
\end{array}\right]\left[\begin{array}{l}
\boldsymbol{e}_{y} \\
\boldsymbol{J} \boldsymbol{e}_{s}
\end{array}\right] \\
& =\left[\begin{array}{ll}
\boldsymbol{I}_{n} & -\left(\boldsymbol{\beta}^{T} \otimes \boldsymbol{I}_{n}\right) \boldsymbol{J}
\end{array}\right] \underbrace{\left[\begin{array}{l}
\boldsymbol{e}_{y} \\
\boldsymbol{e}_{s}
\end{array}\right]}_{\boldsymbol{e}} \\
& =\underbrace{\left[\begin{array}{ll}
\boldsymbol{I}_{n} & \left(\boldsymbol{I}_{n} \otimes \boldsymbol{K}\right)
\end{array}\right]}_{\boldsymbol{D}} \underbrace{\left[\begin{array}{c}
\boldsymbol{e}_{y} \\
\boldsymbol{e}_{s}
\end{array}\right]}_{\boldsymbol{e}}=\boldsymbol{D e}
\end{aligned}
$$

Therefore the nonlinear Gauss-Helmert model (15) may be written according to the original error vector $\boldsymbol{e}$ as follows;

$\Psi(\boldsymbol{\beta}, \boldsymbol{e})=\left(\boldsymbol{A}-\boldsymbol{E}_{A}\right) \boldsymbol{\beta}-\left(\boldsymbol{y}-\boldsymbol{e}_{y}\right)=\boldsymbol{A} \boldsymbol{\beta}+\boldsymbol{D} \boldsymbol{e}-\boldsymbol{y}=\mathbf{0}$

with $\boldsymbol{C}_{e}=\sigma_{0}^{2} \boldsymbol{Q}_{e}$

Its initial linearization is already given by the equations from Eq. (28) to (31). It is also solved iteratively but now predicting the original error vector $\boldsymbol{e}$. For instance, for the first iteration solving model (31) results in the following prediction;

$$
\begin{aligned}
\tilde{\boldsymbol{e}}_{1} & =\left[\begin{array}{c}
\tilde{\boldsymbol{e}}_{y, 1} \\
\tilde{\boldsymbol{e}}_{s, 1}
\end{array}\right] \\
& =\left(\left[\begin{array}{c}
\boldsymbol{Q}_{y}+\boldsymbol{Q}_{y s} \boldsymbol{F}_{0}^{T} \\
\boldsymbol{Q}_{s y}+\boldsymbol{Q}_{s} \boldsymbol{F}_{0}^{T}
\end{array}\right]\right) \boldsymbol{Q}_{1,1}^{-1}\left(\boldsymbol{y}-\boldsymbol{E}_{A, 0} \boldsymbol{\beta}_{0}-\left(\boldsymbol{A}-\boldsymbol{E}_{A, 0}\right) \hat{\boldsymbol{\beta}}_{1}\right)
\end{aligned}
$$

where $\hat{\boldsymbol{\beta}}_{1}$ is the estimated parameter vector as given by Eq. (21) and $\boldsymbol{Q}_{1,1}$ is the cofactor matrix of the error term " $\boldsymbol{\varepsilon}_{0}=\boldsymbol{D}_{0} \boldsymbol{e}$ ", which is identical with the one in Eq. (23) but here is obtained equivalently by

$$
\boldsymbol{Q}_{1,1}=\boldsymbol{D}_{0} \boldsymbol{Q}_{e} \boldsymbol{D}_{0}^{T}=\boldsymbol{Q}_{y}+\boldsymbol{Q}_{y s} \boldsymbol{F}_{0}^{T}+\boldsymbol{F}_{0} \boldsymbol{Q}_{s y}+\boldsymbol{F}_{0} \boldsymbol{Q}_{s} \boldsymbol{F}_{0}^{T}
$$

From Eq. (3) the prediction of the error matrix $\boldsymbol{E}_{A}$ is set as follows;

$$
\tilde{\boldsymbol{E}}_{A, 1}=\left[\begin{array}{cccccc}
\vdots & & & & & \vdots \\
0 & 0 & \tilde{e}_{u_{i}, 1} & -\tilde{e}_{v_{i}, 1} & 0 & 0 \\
0 & 0 & 0 & 0 & \tilde{e}_{u_{i}, 1} & \tilde{e}_{v_{i}, 1} \\
\vdots & & & & & \vdots
\end{array}\right]
$$

where the errors are taken from the error vector $\tilde{\boldsymbol{e}}_{s, 1}=\left[\ldots \tilde{e}_{u i, 1} \tilde{e}_{v i, 1} \ldots\right]^{T}$ predicted by Eq. (34).

The equations between Eq. (24) and (31) show how to set the adjustment procedure solving the corresponding problem in a classical way. This is naturally an iterative procedure. 
Similar to the WTLS algorithms, this iterative adjustment procedure may be defined as an iterative algorithm (Fig 1). Already, Eqs. (32) and (33) prove that this procedure is equivalent to the solution in the previous section. So it is not a different algorithm from the least-squares based-WTLS algorithm. However differently it uses the coordinates' cofactor matrices $\left(\boldsymbol{Q}_{y}, \boldsymbol{Q}_{s}\right.$ and $\left.\boldsymbol{Q}_{y s}=\boldsymbol{Q}_{s y}{ }^{T}\right)$ instead of the cofactor matrices associated with $\boldsymbol{A}$ and $\boldsymbol{y}\left(\boldsymbol{Q}_{y}, \boldsymbol{Q}_{A}\right.$ and $\left.\boldsymbol{Q}_{y A}=\boldsymbol{Q}_{A y}{ }^{T}\right)$.

Take initial values $\hat{\boldsymbol{\beta}}_{0}$ and $\tilde{\boldsymbol{E}}_{A, 0}$ as defined in Eq. (13)

Repeat for $j=1,2 \ldots$

$$
\begin{aligned}
& \boldsymbol{K}_{j-1}=\left[\begin{array}{cc}
-\hat{k}_{1, j-1} & \hat{k}_{2, j-1} \\
-\hat{k}_{3, j-1} & -\hat{k}_{4, j-1}
\end{array}\right], \boldsymbol{F}_{j-1}=\left(\boldsymbol{I}_{n} \otimes \boldsymbol{K}_{j-1}\right), \\
& \boldsymbol{Q}_{1, j}=\boldsymbol{Q}_{y}+\boldsymbol{Q}_{y s} \boldsymbol{F}_{j-1}{ }^{T}+\boldsymbol{F}_{j-1} \boldsymbol{Q}_{s y}+\boldsymbol{F}_{j-1} \boldsymbol{Q}_{s} \boldsymbol{F}_{j-1}{ }^{T}, \boldsymbol{P}_{1, j}=\boldsymbol{Q}_{1, j}^{-1} \\
& \tilde{\boldsymbol{A}}_{j}=\boldsymbol{A}-\tilde{\boldsymbol{E}}_{A, j-1}, \tilde{\boldsymbol{y}}_{j}=\boldsymbol{y}-\tilde{\boldsymbol{E}}_{A, j-1} \hat{\boldsymbol{\beta}}_{j-1}, \\
& \hat{\boldsymbol{\beta}}_{j}=\left(\tilde{\boldsymbol{A}}_{j}^{T} \boldsymbol{P}_{1, j} \tilde{\boldsymbol{A}}_{j}\right)^{-1} \tilde{\boldsymbol{A}}_{j}^{T} \boldsymbol{P}_{1, j} \tilde{\boldsymbol{y}}_{j} \\
& \tilde{\boldsymbol{e}}_{s, j}=\left(\boldsymbol{Q}_{s y}+\boldsymbol{Q}_{s} \boldsymbol{F}_{j-1}{ }^{T}\right) \boldsymbol{P}_{1, j}\left(\tilde{\boldsymbol{y}}-\tilde{\boldsymbol{A}}_{j} \hat{\boldsymbol{\beta}}_{j}\right) \text { and set } \tilde{\boldsymbol{E}}_{A, j} \text { as in Eq (36). }
\end{aligned}
$$

Until " $\max \left(\left|\hat{\boldsymbol{\beta}}_{j}-\hat{\boldsymbol{\beta}}_{j-1}\right|\right)$ " is smaller than a predefined threshold value

Fig 1. Iterative adjustment procedure for correlated coordinates in 2D Affine transformation

The iterative adjustment results in the unknown parameter vector $\hat{\boldsymbol{\beta}}$ whereas the original total error vector $\tilde{\boldsymbol{e}}$ is predicted with Eq. (34) after converging of the iteration. The quadratic form $\tilde{\Omega}$ in Eq. (8) is equivalently obtained by the error vector $\tilde{\boldsymbol{e}}$ as $\tilde{\Omega}=\tilde{\boldsymbol{e}}^{\mathrm{T}} \boldsymbol{Q}_{\mathrm{e}}^{-1} \tilde{\boldsymbol{e}}$. Hence, the covariance matrix of the estimated transformation parameters is obtained considering Eq. (14).

\section{Fixing numerical problems}

Geodetic coordinates transformed each other are generally large numbers. This causes some numerical errors while solving normal equations as it is well known in least-squares adjustment. The coefficients of the matrix $\boldsymbol{A}$ as well as the observations are generally shifted and properly scaled to remove such errors. Here we examine how to handle with this problem in EIV models using the explicit equations given in the previous section.

For the translation parameters $t_{1}$ and $t_{2}$, the following equalities may be considered;

Table 1. Point coordinates and their weights in target and start systems (Aydın et al. 2014) $t_{1}=x_{s}-u_{s} k_{1}+v_{s} k_{2}+\delta t_{1}$ and $t_{2}=y_{s}-u_{s} k_{3}-v_{s} k_{4}+\delta t_{2}$

where $\left(x_{s}, y_{s}\right)$ and $\left(u_{s}, v_{s}\right)$ are the centroid coordinates in the target and the start system, respectively and $\delta t_{1}$ and $\delta t_{2}$ are the unknown small parts of the corresponding translation parameters. With Eq. (37), the observation equations in Eq. (28) changes to

$$
\begin{aligned}
\Delta x_{i}-\left(e_{u i, 0} k_{1,0}-e_{v i, 0} k_{2,0}\right) & =\delta t_{1}+\left(\Delta u_{i}-e_{u i, 0}\right) k_{1}-\left(\Delta v_{i}-e_{v i, 0}\right) k_{2} \\
& +\left(e_{x i}-k_{1,0} e_{u i}+k_{2,0} e_{v i}\right)
\end{aligned}
$$

$(i=1, \ldots, p)$

$$
\begin{aligned}
\Delta y_{i}-\left(e_{u i, 0} k_{3,0}+e_{v i, 0} k_{4,0}\right)= & \delta t_{2}+\left(\Delta u_{i}-e_{u i, 0}\right) k_{3}+\left(\Delta v_{i}-e_{v i, 0}\right) k_{4} \\
& +\left(e_{y i}-k_{3,0} e_{u i}-k_{4,0} e_{v i}\right)
\end{aligned}
$$

$(i=1, \ldots, p)$

where the coordinates with " $\Delta$ " represent the shifted coordinates

$$
\Delta x_{i}=x_{i}-x_{s}, \Delta y_{i}=y_{i}-y_{s}, \Delta u_{i}=u_{i}-u_{s}, \Delta v_{i}=v_{i}-v_{s}
$$

Eq. (38) shows that the solution may be realized by these shifted coordinates instead of the original coordinates. In such a solution, the data matrix $(A)$, the vector of target sys-

\begin{tabular}{|c|c|c|c|c|c|c|c|c|}
\hline \multirow{2}{*}{ NN } & \multicolumn{4}{|c|}{ Target System } & \multicolumn{4}{|c|}{ Start System } \\
\hline & $x(m)$ & $y(m)$ & $P_{x}\left(m^{-2}\right)$ & $P_{y}\left(m^{-2}\right)$ & $\mathrm{u}(\mathrm{m})$ & $v(m)$ & $P_{u}\left(m^{-2}\right)$ & $P_{v}\left(m^{-2}\right)$ \\
\hline 1 & 4527754,612 & 434244,302 & 1,0 & 2,0 & $-12681,216$ & $-11115,112$ & 30,0 & 10,0 \\
\hline 2 & 4529097,150 & 432427,995 & 5,0 & 2,0 & $-10849,480$ & $-9793,890$ & 4,0 & 20,0 \\
\hline 3 & 4537389,003 & 434023,394 & 10,0 & 1,0 & $-12348,250$ & $-1484,610$ & 50,0 & 1,6 \\
\hline 4 & 4533316,751 & 429750,773 & 5,0 & 2,0 & $-8123,500$ & $-5605,860$ & 50,0 & 2,4 \\
\hline 5 & 4534306,216 & 426390,182 & 4,0 & 0,5 & $-4751,710$ & $-4655,920$ & 1,3 & 3,2 \\
\hline 6 & 4530615,243 & 427898,173 & 4,0 & 10,5 & $-6302,628$ & $-8328,789$ & 1,4 & 36,0 \\
\hline
\end{tabular}
tem coordinates $(\boldsymbol{y})$, unknown parameter vector $(\boldsymbol{\beta})$ of the algorithm given in the previous section are replaced by

$$
\begin{aligned}
& \boldsymbol{A}=\left[\begin{array}{cccccc}
\vdots & & & & \vdots \\
1 & 0 & \Delta u_{i} & -\Delta v_{i} & 0 & 0 \\
0 & 1 & 0 & 0 & \Delta u_{i} & \Delta v_{i} \\
\vdots & & & \vdots
\end{array}\right], \\
& \boldsymbol{y}=\left[\begin{array}{c}
\vdots \\
\Delta x_{i} \\
\Delta y_{i} \\
\vdots
\end{array}\right], \quad \boldsymbol{\beta}=\left[\begin{array}{c}
\delta t_{1} \\
\delta t_{2} \\
k_{1} \\
k_{2} \\
k_{3} \\
k_{4}
\end{array}\right]
\end{aligned}
$$

\section{Numerical Example}

In order to apply the iterative adjustment procedure to $2 \mathrm{D}$ Affine transformation problem, the data given in Aydin et al. (2014) is used herein. The data includes six points' coordinates and their weights in two systems (Table 1). 
Table 2. Centered coordinates

\begin{tabular}{lcccc}
\hline $\mathrm{NN}$ & $\Delta \mathrm{x}(\mathrm{m})$ & $\Delta \mathrm{y}(\mathrm{m})$ & $\Delta \mathrm{u}(\mathrm{m})$ & $\Delta \mathrm{v}(\mathrm{m})$ \\
\hline 1 & $-4325,2172$ & 3455,1655 & $-3505,0853$ & $-4284,4152$ \\
\hline 2 & $-2982,6792$ & 1638,8585 & $-1673,3493$ & $-2963,1932$ \\
\hline 3 & 5309,1738 & 3234,2575 & $-3172,1193$ & 5346,0868 \\
\hline 4 & 1236,9218 & $-1038,3635$ & 1052,6307 & 1224,8368 \\
\hline 5 & 2226,3868 & $-4398,9545$ & 4424,4207 & 2174,7768 \\
\hline 6 & $-1464,5862$ & $-2890,9635$ & 2873,5027 & $-1498,0922$ \\
\hline
\end{tabular}

\section{Computation steps:}

i) The coordinates of two systems are translated to the centroid (Table 2), as shown in Eq. (39).

ii) The design matrix $\boldsymbol{A}$ and the vector $\boldsymbol{y}$ are established as given in Eq. (40) using the centered coordinates in Table 2

$$
\begin{aligned}
\boldsymbol{A} & =\left[\begin{array}{cccccc}
1 & 0 & -3505.0853 & 4284.4152 & 0 & 0 \\
0 & 1 & 0 & 0 & -3505.0853 & -4284.4152 \\
\vdots & \vdots & \vdots & \vdots & \vdots & \vdots
\end{array}\right] \\
\boldsymbol{y} & =\left[\begin{array}{c}
-4325.2172 \\
3455.1655 \\
\vdots
\end{array}\right](\mathrm{m})
\end{aligned}
$$

iii) The cofactor matrices of the two system coordinates are set from the weights in Table 1 as follows:

$$
\begin{aligned}
& \boldsymbol{Q}_{y}=\boldsymbol{P}_{y}^{-1}, \boldsymbol{Q}_{s}=\boldsymbol{P}_{s}^{-1} ; \\
& \boldsymbol{P}_{y}=\operatorname{diag}\left(P_{x 1} P_{y 1} \ldots P_{x 6} P_{y 6}\right), \boldsymbol{P}_{s}=\operatorname{diag}\left(P_{u 1} P_{v 1} \ldots P_{u 6} P_{v 6}\right)
\end{aligned}
$$

Because two systems are uncorrelated, we take $\boldsymbol{Q}_{y s}=\boldsymbol{Q}_{s y}=\mathbf{0}$ iv) To start the iterative adjustment procedure, first the parameter vector is estimated by " $\hat{\boldsymbol{\beta}}_{0}=\left(\boldsymbol{A}^{T} \boldsymbol{Q}_{y}^{-1} \boldsymbol{A}\right)^{-1} \boldsymbol{A}^{T} \boldsymbol{Q}_{y}^{-1} \boldsymbol{y}$ " and the error matrix is assumed as " $\tilde{\boldsymbol{E}}_{A, 0}=\mathbf{0}$ ". The estimated parameters are given in Table 3 . As the centered coordinates are used, the estimated vector $\hat{\boldsymbol{\beta}}_{0}$ includes " $\delta t_{1}$ and $\delta t_{2}$ " according to Eqs. (38). (Note: Eq. (37) may be used to compute $t_{1}$ and $t_{2}$.)

Using the initial values defined above, the Jacobian matrix $\boldsymbol{F}_{0}$ is simply set as follows:

Table 3. Least-squares estimates: Initial values of iterative adjustment procedure

\begin{tabular}{cc}
\hline Parameter & LS Estimation \\
$\mathrm{k}_{1}$ & 0,011647225402 \\
$\mathrm{k}_{2}$ & $-1,000003341129$ \\
$\mathrm{k}_{3}$ & $-0,999994105682$ \\
$\mathrm{k}_{4}$ & 0,011640379341 \\
$\delta \mathrm{t}_{1}(\mathrm{~m})$ & $-0,006306254073$ \\
$\delta \mathrm{t}_{2}(\mathrm{~m})$ & $-0,024925406785$ \\
\hline $\mathrm{t}_{1}-4539017(\mathrm{~m})$ & 0,418978172400 \\
$\mathrm{t}_{2}-421692(\mathrm{~m})$ & 0,546897262570 \\
\hline
\end{tabular}

$$
\begin{aligned}
& \boldsymbol{F}_{0}=\left[\begin{array}{ccccc}
-\hat{k}_{1,0} & \hat{k}_{2,0} & \cdots & 0 & 0 \\
-\hat{k}_{3,0} & -\hat{k}_{4,0} & \cdots & 0 & 0 \\
\vdots & \vdots & \ddots & \vdots & \vdots \\
0 & 0 & \cdots & -\hat{k}_{1,0} & \hat{k}_{2,0} \\
0 & 0 & \cdots & -\hat{k}_{3,0} & -\hat{k}_{4,0}
\end{array}\right] \\
& =\left[\begin{array}{ccccc}
-0.0116 \ldots & -1.0000 \ldots & \cdots & 0 & 0 \\
0.9999 \ldots & -0.0116 \ldots & \cdots & 0 & 0 \\
\vdots & \vdots & \ddots & \vdots & \vdots \\
0 & 0 & \cdots & -0.0116 \ldots & -1.0000 \ldots \\
0 & 0 & \cdots & 0.9999 \ldots & -0.0116 \ldots
\end{array}\right]
\end{aligned}
$$

This Jacobian matrix will be improved using the new values of the translation parameters estimated after each iterative solution.

v) Then the problem is solved using the iterative adjustment procedure in Fig 1. In the solution the relative error $\varepsilon=10^{-12}$ was chosen. The algorithm converged to the solution at the third iteration (Table 4). It is important here to inform that the parameter estimates for $\delta t_{1}$ and $\delta t_{2}$ are different at the second and third iterations, however the translation parameters $t_{1}$ and $t_{2}$ obtained from Eq. (37) are not. Therefore we recommend that the convergence check should be realized by comparing the parameter estimates for " $k_{1}, \ldots, k_{4}$ " as well as " $t_{1}$ and $t_{2}$ " between the sequential iterations.

The elements of the error vectors $\tilde{\boldsymbol{e}}_{s}$ and $\tilde{\boldsymbol{e}}_{y}$ of the start and target system coordinates, respectively, which are obtained by (see Eq. (34)):

$$
\begin{aligned}
& \tilde{\boldsymbol{e}}_{s}=\boldsymbol{Q}_{s} \boldsymbol{F}_{2}^{T}\left(\boldsymbol{Q}_{1,3}\right)^{-1}\left(\boldsymbol{y}-\tilde{\boldsymbol{E}}_{A, 2} \boldsymbol{\beta}_{2}-\left(\boldsymbol{A}-\tilde{\boldsymbol{E}}_{A, 2}\right) \hat{\boldsymbol{\beta}}_{3}\right), \\
& \tilde{\boldsymbol{e}}_{y}=\boldsymbol{Q}_{y}\left(\boldsymbol{Q}_{1,3}\right)^{-1}\left(\boldsymbol{y}-\tilde{\boldsymbol{E}}_{A, 2} \boldsymbol{\beta}_{2}-\left(\boldsymbol{A}-\tilde{\boldsymbol{E}}_{A, 2}\right) \hat{\boldsymbol{\beta}}_{3}\right)
\end{aligned}
$$

are given in Table 5.

\begin{tabular}{cccc}
\multicolumn{4}{c}{ Table 4. Parameter estimates in each iteration of iterative adjustment procedure } \\
\hline Parameter & First Iteration & Second Iteration & Third Iteration \\
\hline $\mathrm{k}_{1}$ & 0,011651721701 & 0,011651721608 & 0,011651721608 \\
\hline $\mathrm{k}_{2}$ & $-0,999998393160$ & $-0,999998393604$ & $-0,999998393604$ \\
\hline $\mathrm{k}_{3}$ & $-0,999985854949$ & $-0,999985855098$ & $-0,999985855098$ \\
$\mathrm{k}_{4}$ & 0,011637345550 & 0,011637345558 & 0,011637345558 \\
\hline$\delta \mathrm{t}_{1}(\mathrm{~m})$ & 0,002427902022 & 0,002428130895 & 0,002428130884 \\
$\delta \mathrm{t}_{2}(\mathrm{~m})$ & $-0,010194003949$ & $-0,010194180848$ & $-0,010194180847$ \\
\hline $\mathrm{t}_{1}-4539017(\mathrm{~m})$ & 0,435172882900 & 0,435175295000 & 0,435175295000 \\
$\mathrm{t}_{2}-421692(\mathrm{~m})$ & 0,616615561420 & 0,616614076890 & 0,616614076890 \\
\hline
\end{tabular}


Table 5. Error prediction of two system coordinates

\begin{tabular}{|c|c|c|c|c|}
\hline \multirow{2}{*}{ NN } & \multicolumn{2}{|c|}{ Target System } & \multicolumn{2}{|c|}{ Start System } \\
\hline & $e_{x}(m)$ & $e_{y}(m)$ & $e_{u}(m)$ & $e_{v}(m)$ \\
\hline 1 & 0,026335508457 & $-0,000806861724$ & $-0,000064018488$ & $-0,002631668669$ \\
\hline 2 & 0,003436019974 & 0,017848736298 & 0,008874197479 & $-0,000879774805$ \\
\hline 3 & 0,007442742337 & $-0,021129326553$ & $-0,000439924706$ & $-0,046363384087$ \\
\hline 4 & $-0,058543186238$ & 0,009588529504 & 0,000451748646 & 0,121871787879 \\
\hline 5 & 0,026284431422 & 0,076344315865 & 0,028420448062 & $-0,032994306058$ \\
\hline 6 & 0,017408793497 & $-0,006695584718$ & $-0,050795724831$ & $-0,001911580955$ \\
\hline
\end{tabular}

vi) Using the final predicted errors of the two system coordinates given in Table 5, the variance component is computed as

$$
\hat{\sigma}^{2}=\frac{\tilde{\Omega}}{n-6}=\frac{\tilde{\boldsymbol{e}}^{T} \boldsymbol{Q}_{e}^{-1} \tilde{\boldsymbol{e}}}{n-6}=\frac{\tilde{\boldsymbol{e}}_{y}^{T} \boldsymbol{Q}_{y}^{-1} \tilde{\boldsymbol{e}}_{y}+\tilde{\boldsymbol{e}}_{s}^{T} \boldsymbol{Q}_{s}^{-1} \tilde{\boldsymbol{e}}_{s}}{12-6}=0.012475937055
$$

The covariance matrix of the estimated parameters are then estimated from Eq. (14) as follows;

$$
\boldsymbol{C}_{\hat{\beta}}=\hat{\sigma}^{2}\left[\left(\boldsymbol{A}-\tilde{\boldsymbol{E}}_{A, 2}\right)^{T} \boldsymbol{Q}_{1,3}^{-1}\left(\boldsymbol{A}-\tilde{\boldsymbol{E}}_{A, 2}\right)\right]^{-1}
$$

Since we work with the centered coordinates, the above covariance matrix belongs to the parameters " $\delta t_{1}, \delta t_{2}, k_{1}, \ldots, k_{4}$ ". To obtain the covariance matrix of the translation parameters $t_{1}$ and $t_{2}$, we use the following equation, which is obtained by applying covariance propagation rule to Eqs. (37),

$$
\boldsymbol{C}_{t}=\boldsymbol{H C}_{\hat{\beta}} \boldsymbol{H}^{T} \text { with } \boldsymbol{H}=\left[\begin{array}{cccccc}
1 & 0 & -u_{s} & v_{s} & 0 & 0 \\
0 & 1 & 0 & 0 & -u_{s} & -v_{s}
\end{array}\right]
$$

The standard deviations of the parameters $\left(k_{1}, \ldots, k_{4}, \delta t_{1}, \delta t_{2}\right.$ as well as $t_{1}$ and $t_{2}$ ) are given in Table 6 .

Accordingly it is seen that the estimated parameters and their standard deviations obtained from the iterative adjustment procedure given here are equal to the ones in Aydin et al. (2014). Hence we conclude that the iterative adjustment procedure is also consistent with the WTLS solution numerically.

\section{Conclusion}

This study discusses the solution of the coordinate transformation problem within the EIV model in a classical adjustment way using the ideas of "generalization of TLS" and " general least-squares method" given by Neitzel (2010) and Ghilani and Wolf (2006), respectively. It is shown that the derived iterative adjustment procedure for this aim is equivalent to the least-squares WTLS algorithm. So it is not a new method but it has some advantages: (1) For adapting a WTLS algorithm for solving the transformation problem within the EIV model, the cofactor matrix of the design matrix $(\mathbf{A})$ and the target system coordinates ( $\mathbf{y})$ is needed. For this, a special modification procedure should be taken into account as mentioned in Section 2. However, the iterative adjustment procedure works with the original (given) cofactor matrix of coordinates. Therefore, in this procedure there is no any additional burden for the setting the stochastic part of the model. (2) One may derive explicitly the iterative equations of the procedure just considering the partial derivatives of the errors and unknown parameters for any EIV model. The geodetic community is more familiar with the linearization procedure for solving the nonlinear models in such a way. Hence, adapting other known statistical and numerical methods to the EIV model is easier when such an adjustment procedure is considered.

In this study, 2D Affine transformation is examined. However, the iterative adjustment procedure and the technique for usage of the centered coordinates in the iterative estimation process are easily applicable to the other geodetic transformation problems, such as 7 parameter-Helmert and 9 parameter-Affine transformation problems. In such problems, considering only the centered coordinates may not solve the corresponding numerical errors. Then it is advisable to consider centered and normalized coordinates. The iterative equations of the procedure discussed here do not change, however one should consider the true equations to get the desired translation parameters after each iteration to set the next iterations' input values.

\section{Appendix A}

With the following $n \times n(n=2 p)$ permutation matrices

$$
\begin{aligned}
& \boldsymbol{D}_{j}=\boldsymbol{I}_{p} \otimes \boldsymbol{K}_{j} \\
& \left(\begin{array}{l}
j=3,4,5,6 \text { and } \\
\left.\boldsymbol{K}_{3}=\left[\begin{array}{ll}
1 & 0 \\
0 & 0
\end{array}\right], \boldsymbol{K}_{4}=\left[\begin{array}{cc}
0 & -1 \\
0 & 0
\end{array}\right], \boldsymbol{K}_{5}=\left[\begin{array}{ll}
0 & 0 \\
1 & 0
\end{array}\right], \boldsymbol{K}_{6}=\left[\begin{array}{ll}
0 & 0 \\
0 & 1
\end{array}\right]\right)
\end{array}\right.
\end{aligned}
$$

the random error vector $\boldsymbol{e}_{s}$ is transformed to the vectorized form of the error matrix $\mathbf{E}_{A}$ by

Table 6. Standard deviations of the estimated parameters

\begin{tabular}{|cc|}
\hline Parameter & Standard Deviation \\
\hline$k_{1}$ & 0,000011320243 \\
\hline$k_{2}$ & 0,000011032937 \\
\hline$k_{3}$ & 0,000015787378 \\
\hline$k_{4}$ & 0,000013057698 \\
\hline$\delta t_{1}(m)$ & 0,031875120007 \\
\hline$\delta t_{2}(m)$ & 0,041893765662 \\
$t_{1}(m)$ & 0,121461424911 \\
$t_{2}(m)$ & 0,167012387036 \\
\hline
\end{tabular}


$\boldsymbol{e}_{A}=\operatorname{vec} \boldsymbol{E}_{A}=\left[\begin{array}{c}\mathbf{0} \\ \mathbf{0} \\ \boldsymbol{D}_{3} \\ \boldsymbol{D}_{4} \\ \boldsymbol{D}_{5} \\ \boldsymbol{D}_{6}\end{array}\right]=\boldsymbol{J} \boldsymbol{e}_{s}$

which defines the $6 n \times n$ Jacobian matrix $\mathbf{J}$.

\section{Appendix B: Least-squares based-WTLS algorithm for correlated observables}

Take initial values $\hat{\boldsymbol{\beta}}_{0}$ and $\tilde{\boldsymbol{E}}_{A, 0}$ as defined in Eq (13)

Repeat for $j=1,2 \ldots$

$\boldsymbol{L}_{j}=\hat{\boldsymbol{\beta}}_{j-1} \otimes \boldsymbol{I}_{n}, \boldsymbol{Q}_{1, j}=\boldsymbol{Q}_{y}-\boldsymbol{Q}_{y A} \boldsymbol{L}_{j}-\boldsymbol{L}_{j}^{T} \boldsymbol{Q}_{A y}+\boldsymbol{L}_{j}^{T} \boldsymbol{Q}_{A} \boldsymbol{L}_{j}, \boldsymbol{P}_{1, j}=\boldsymbol{Q}_{1, j}^{-1}$

$\tilde{\boldsymbol{A}}_{j}=\boldsymbol{A}-\tilde{\boldsymbol{E}}_{A, j-1}, \tilde{\boldsymbol{y}}_{j}=\boldsymbol{y}-\tilde{\boldsymbol{E}}_{A, j-1} \hat{\boldsymbol{\beta}}_{j-1}, \hat{\boldsymbol{\beta}}_{j}=\left(\tilde{\boldsymbol{A}}_{j}^{T} P_{1, j} \tilde{\boldsymbol{A}}_{j}\right)^{-1} \tilde{\boldsymbol{A}}_{j}^{T} P_{1, j} \tilde{\boldsymbol{y}}_{j}$

$\tilde{\boldsymbol{e}}_{A, j}=\left(\boldsymbol{Q}_{A y}-\boldsymbol{Q}_{A}\left(\hat{\boldsymbol{\beta}}_{j} \otimes \boldsymbol{I}_{n}\right)\right) \boldsymbol{P}_{1, j}\left(\tilde{\boldsymbol{y}}_{j}-\tilde{\boldsymbol{A}}_{j} \hat{\boldsymbol{\beta}}_{j}\right)$ and $\tilde{\boldsymbol{E}}_{A, j}=\operatorname{vec}^{-1}\left(\tilde{\boldsymbol{e}}_{A, j}\right)$

Until " $\max \left(\left|\hat{\boldsymbol{\beta}}_{j}-\hat{\boldsymbol{\beta}}_{j-1}\right|\right) "$ is smaller than a predefined threshold value.

\section{References}

Amiri-Simkooei, A. and Jazaeri, S., (2012), Weighted total leastsquares formulated by standard least squares theory, Journal of Geodetic Science 2(2): pp.113-124.

Aydın, C., Uygur M., Uygur S. Ö., (2014), Ağırlıkl toplam en küçük kareler çözümü: Üç farkll algoritma ve 2-boyutlu Afin dönüşümüne uygulanması, Harita Dergisi, Sayı 152, 1-11.

Carroll, R.J. and Ruppert, D., (1996), The use and misuse of orthogonal regression in linear errors-in-variables models, The American Statistician, 50(1): pp. 1-6.

Fang, X., (2011), Weighted total least squares solutions for applications in geodesy, $\mathrm{PhD}$ Dissertation, Geodaesie und Geoinformatik Der Leibniz Universitaet Hannover, Hannover.
Fang, X., (2013), Weighted total least squares: necessary and sufficient conditions, fixed and random parameters, Journal of Geodesy, 87: pp. 733-749.

Ghilani, C.D. and Wolf, P.R., (2006), Adjustment computations: Spatial Data Analysis, Fourth Edition, John Wiley\&Sons Inc., Hoboken, New Jersey.

Golub, G.H. and van Loan, C.F., (1980), An analysis of the total least squares problem, SIAM J. Numer. Anal., 17(6): pp. 883893.

Koch, K.R., (1999), Parameter estimation and hypothesis testing in linear models, Second Edition, Springer-Verlag, Berlin/ Heidelberg.

Neitzel, F., (2010), Generalization of total least-squares on example of unweighted and weighted $2 D$ similarity transformation, Journal of Geodesy, 84(12): pp. 751-762.

Pope, A. J., (1972), Some pitfalls to be avoided in the iterative adjustment of nonlinear problems, In: Proceedings of the 38th Annual Meeting of the American Society of Photogrammetry, Washington DC: pp. 449-477.

Schaffrin, B. and Wieser, A., (2008), On weighted total leastsquares adjustment for linear regression, Journal of Geodesy, 82: pp. 415-421.

Schaffrin, B. and Snow, K., (2010), Total least-squares regularization of Tykhonov type and an ancient racetrack in Corinth, Linear Algebra and its Applications, 432(8): pp. 20612076.

Snow, K., (2012), Topics in total least-squares adjustment within the errors-in-variables model: Singular cofactor matrices and prior information, Report No. 502, Geodetic Science Ohio State University, Columbus, Ohio.

Tong, X., Jin, Y., Li, L., (2011), An improved weighted total least squares method with applications in linear fitting and coordinate transformation, Journal of Surveying Engineering, 137(4): pp. $120-128$.

Van Huffel, S., (2004), Total least-squares and errors-in-variables modeling: Bridging the gap between statistics, computational mathematics and engineering, COMPSTAT 2004 Symposium, Physica-Verlag/Springer: pp. 1-16. 